\title{
The variability of C-F bonds governs the formation of specific structural motifs in fluorinated graphenes
}

Rostislav Langer, ${ }^{\# 1,2}$ Dagmar Zaoralová, ${ }^{\# 1,2}$ Miroslav Medved, ${ }^{* 1}$ Pavel Banáś, ${ }^{1,2}$ Piotr Btoński, ${ }^{* 1}$ and Michal Otyepka*1,2

\# These authors contributed equally to this work

${ }^{1}$ Regional Centre of Advanced Technologies and Materials, Faculty of Science, Palacký University in Olomouc, Šlechtitelů 27, 78371 Olomouc, Czech Republic.

${ }^{2}$ Department of Physical Chemistry, Faculty of Science, Palacký University in Olomouc, 17. listopadu 12, 77146 Olomouc, Czech Republic.

\section{The remarkable variability of C-F bonds}

The calculated range of bond lengths in pFGs (Figure 1a) is up-shifted by ca. 0.1-0.2 $\AA$ compared to typical C-F bonds in aromatic organic compounds that is shown in histogram based on Cambridge Crystallographic Data Centre $(\mathrm{CCDC})(\mathrm{S} 1)$ data in Figure S1. Groups in Figure 1a were divided according to the position and number of adjoining C-F bonds (Figure S2). To derive the rules that govern the C-F bond strength we have calculated additional characteristics of C-F bonds. Namely, we evaluated the number of adjoining C-F bonds in cis and trans positions, deformation energy $\left(\mathrm{kcal} \cdot \mathrm{mol}^{-1}\right)$ that is needed for distortion of the graphene plane due to the $\mathrm{C}-\mathrm{F}$ bond formation, polarity of $\mathrm{C}-\mathrm{F}$ bond $(e)$, average $\mathrm{C}-\mathrm{C}-\mathrm{F}$ angle $\left(^{\circ}\right)$ and the number of $\mathrm{C}-\mathrm{C}$ bonds that participate in $\pi$-conjugation of the material after the dissociation of the considered C-F bond (further only term " $\pi$-conjugation" is used). We used statistical methods to look for correlations among these properties. 


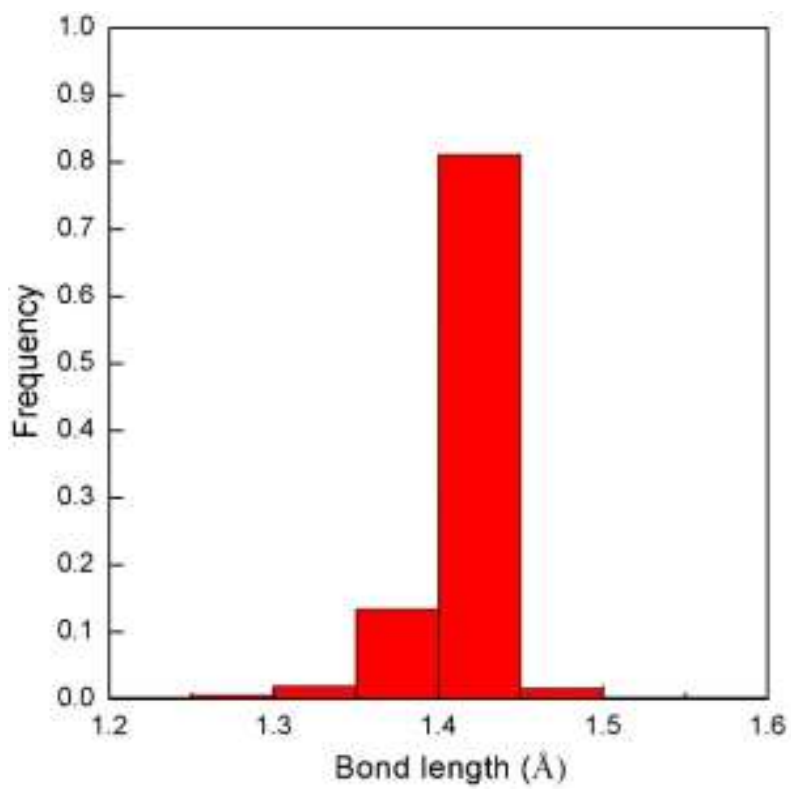

Figure S1. C-F bond lengths in aromatic organic compounds based on CCDC data. 


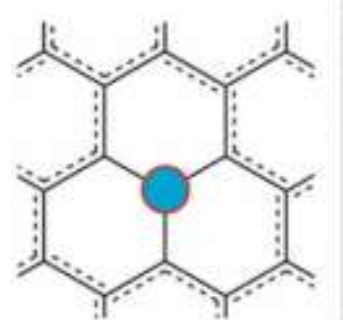

$\mathrm{C}_{32} \mathrm{~F}$

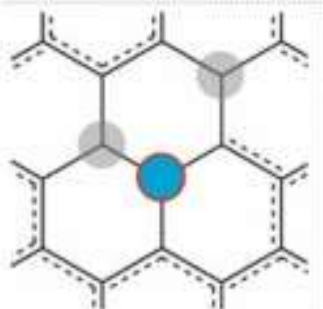

IF in trans position

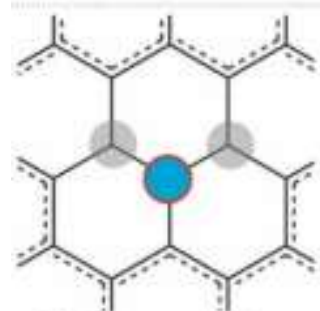

$2 \mathrm{~F}$ in trans position

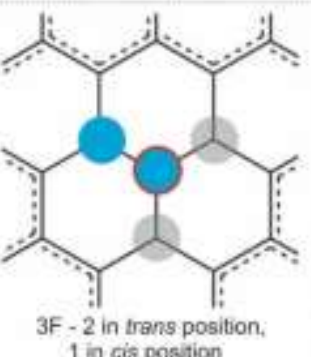

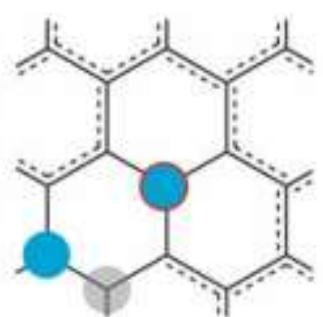

isolated $\mathrm{F}$

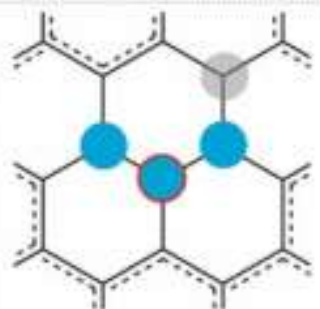

$2 \mathrm{~F}$ in cis position

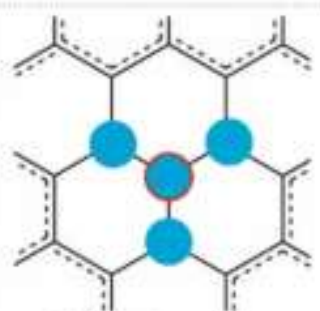

$3 \mathrm{~F}$ in cis position

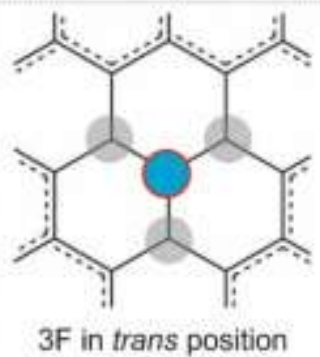

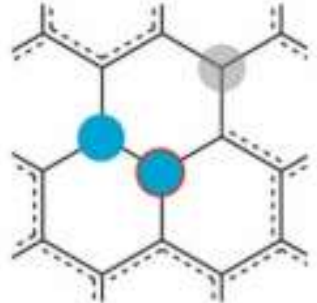

$1 \mathrm{~F}$ in cis position<smiles>CC=CCOC1CCC1</smiles>

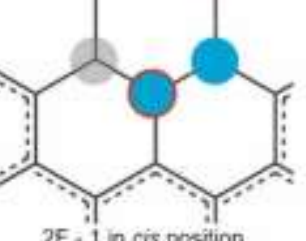
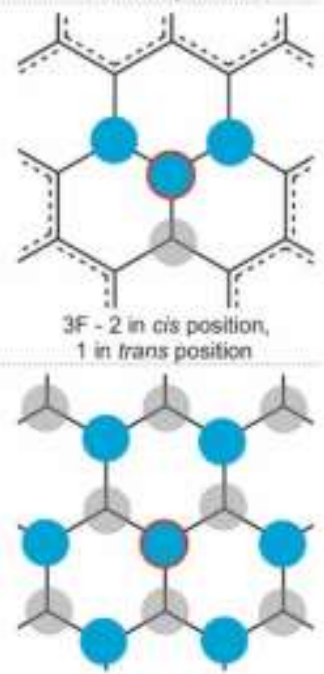

Fluorographene

Figure S2. Configurations of pFGs divided according to the number and position of neighboring fluorine ad-atom(s) to the considered C-F bond (marked red). BDEs of considered C-F bonds are in Figure 1a. Fluorine ad-atoms projecting above and below the graphene sheet are represented by blue and grey circles, respectively.

Pair correlations of BDE and other descriptors (Figure S3) show that BDE is mostly influenced by the $\pi$-conjugation (coefficient of determination, $R^{2}=0.53$ ) and the number of neighboring $\mathrm{F}$ ad-atoms in trans position $\left(R^{2}=0.55\right)$. 

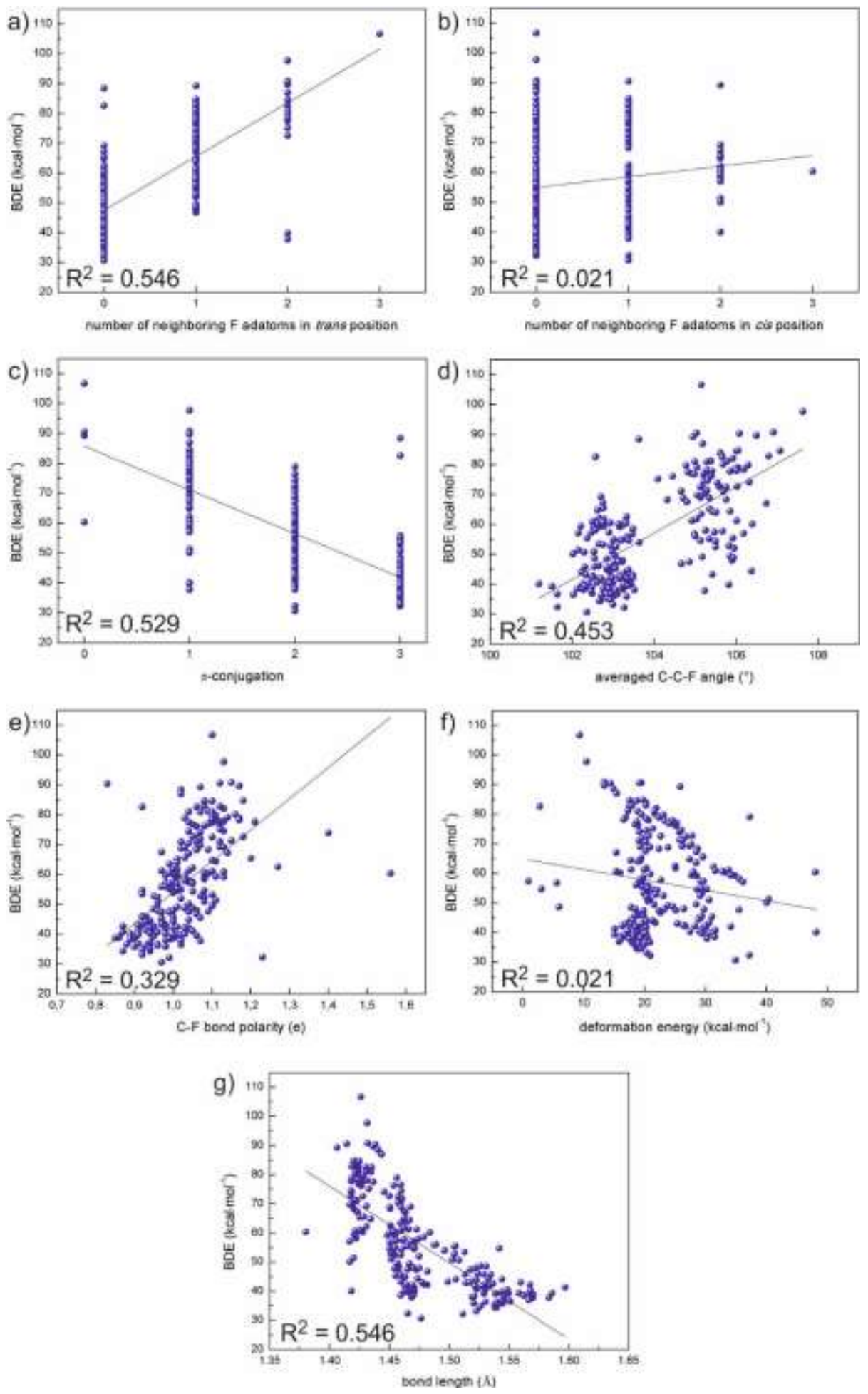

Figure S3. Pair correlations of BDE and a) the number of neighboring $\mathrm{F}$ ad-atoms in trans position, $\mathrm{b}$ ) the number of neighboring $\mathrm{F}$ ad-atoms in cis position, c) $\pi$-conjugation, d) averaged C-C-F angle, e) C-F bond polarity, f) deformation energy, g) bond length. 
The significant influence of the number fluorine ad-atoms in trans position on BDE suggests that BDE could be related to the deformation of the graphene plane. However, BDE does not correlate with deformation energy $\left(R^{2}=0.02\right.$, Figure S3f $)$ nor with the number of ad-atoms in cis position $\left(R^{2}=0.02\right.$, Figure $\left.\mathbf{S 3 b}\right)$. On the other hand, deformation energy is significantly influenced by the number of ad-atoms in cis position $\left(R^{2}=0.57\right.$, Figure S4). To eliminate the influence of $\pi$ conjugation on BDE, we have divided C-F bonds into groups according to the number of neighboring C-F bonds. Since deformation of the graphene plane is also influenced by the stoichiometry of the material, the structures were further subdivided according to their composition. Figure S5 shows an example of four configurations of the same stoichiometry in which the red marked $\mathrm{F}$ ad-atom has the same number of neighboring $\mathrm{C}-\mathrm{F}$ bonds. It demonstrates significant influence of deformation energy on BDE $\left(R^{2}=0.97\right)$. However, not for all groups of structures divided according to the stoichiometry and the number of neighboring C-F bonds BDE correlates so strongly with the deformation energy (see Table S1). Generally, more densely packed C-F bonds are influenced more by the deformation energy, e.g. BDEs for configurations with chains or rings of $\mathrm{F}$ ad-atoms strongly correlate with deformation energy $\left(R^{2}>0.9\right)$ but BDEs of C-F bonds with one or none neighboring $\mathrm{F}$ ad-atom are less influenced by structural distortions $\left(0.4<R^{2}<0.7\right)$

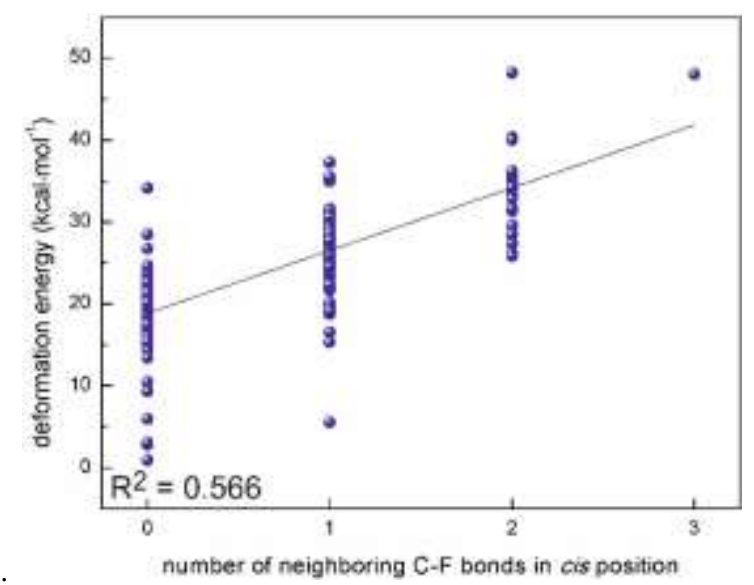

Figure S4. Pair correlation of deformation energy and the number of neighboring C-F bonds in cis position. 


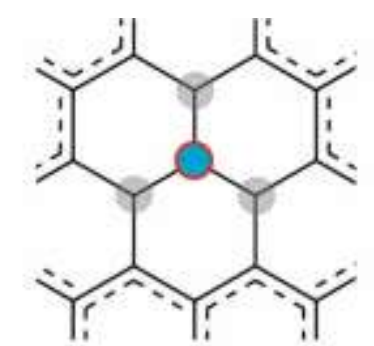

$\mathrm{BDE}=106.7 \mathrm{kcal} \cdot \mathrm{mol}^{-1}$ $E_{\text {def }}=9.3 \mathrm{kcal} \cdot \mathrm{mol}^{-1}$

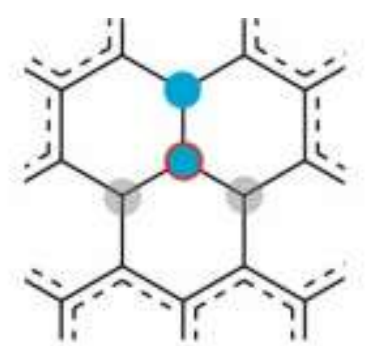

$\mathrm{BDE}=90.6 \mathrm{kcal} \cdot \mathrm{mol}^{-1}$ $E_{\text {def }}=19.1 \mathrm{kcal} \cdot \mathrm{mol}^{-1}$

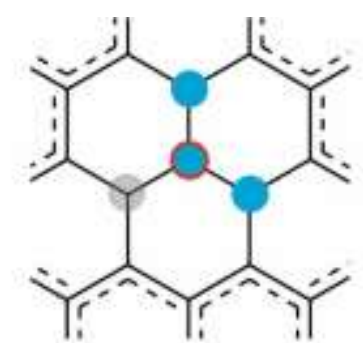

$\mathrm{BDE}=89.3 \mathrm{kcal} \cdot \mathrm{mol}^{-1}$

$E_{\text {def }}=19.6 \mathrm{kcal} \cdot \mathrm{mol}^{-1}$

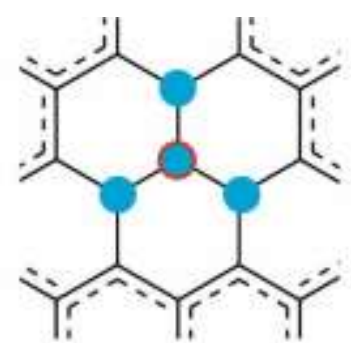

$\mathrm{BDE}=60.4 \mathrm{kcal} \cdot \mathrm{mol}^{-1}$

$E_{\text {def }}=48.0 \mathrm{kcal} \cdot \mathrm{mol}^{-1}$

Figure S5. Example of four configurations with the same stoichiometry in which BDE of the red marked C-F bond is strongly influenced by the deformation energy $\left(\mathrm{E}_{\mathrm{def}}\right)$.

Previous studies (S2, S3) demonstrated that C-F bond changes from semi-ionic to covalent with increasing fluorine content and that the decrease of $\mathrm{C}-\mathrm{F}$ bond polarity is accompanied by $\mathrm{C}$-F bond shortening. To confirm this statement, we have assessed a pair correlation of the C-F bond polarity with the C-F bond length $\left(R^{2}=0.55\right.$, Figure S6a) showing less significant correlation than in the work by Zhou et al.(S2) However, our data include also less favorable geometries (with C-F bonds in cis position) that were not considered in Ref.(S2). Therefore, the pair correlations were carried out again for the most stable structures only (with C-F bonds in trans position). It showed much stronger correlation of the C-F bond polarity and bond length $\left(R^{2}=0.93\right.$, Figure $\left.\mathbf{S 6 b}\right)$. 

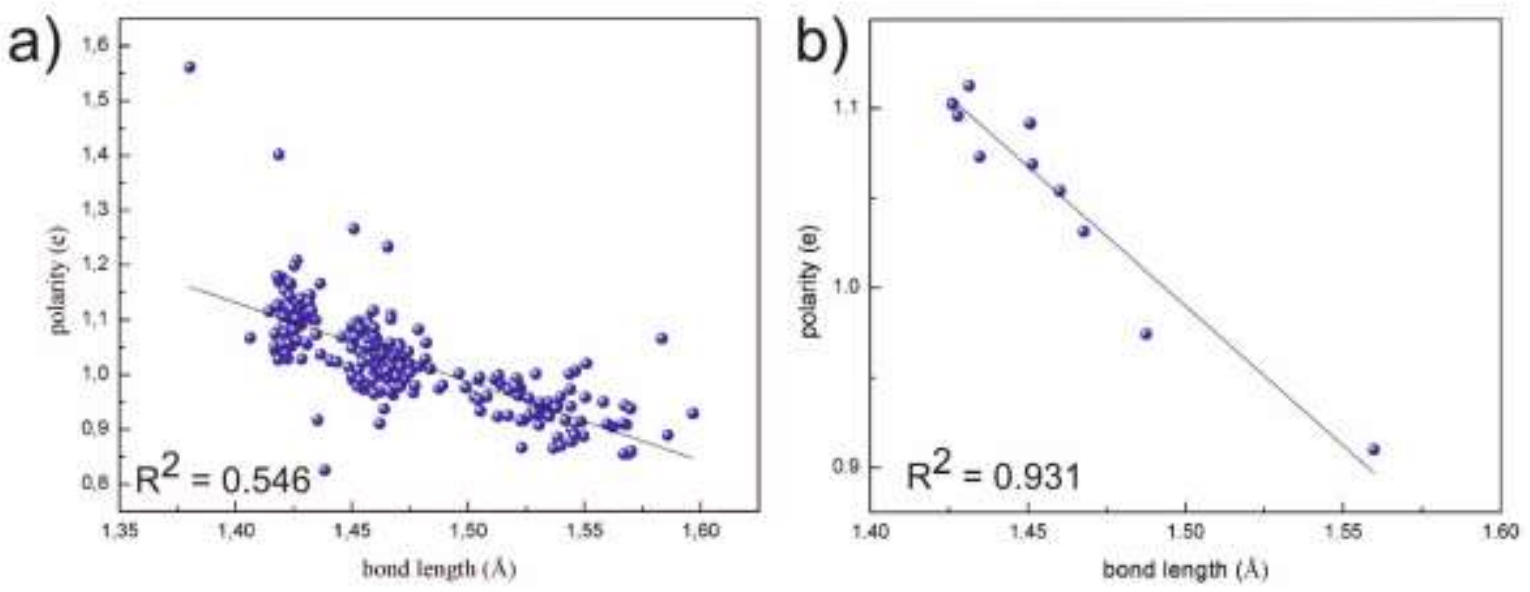

Figure S6. Pair correlation of C-F bond polarity and C-F bond length of a) all calculated structures and b) the most stable structures.

Table S1. Correlation coefficients $\left(R^{2}\right)$ for pair correlations between BDE and deformation energy (in $\mathrm{kcal} \cdot \mathrm{mol}^{-1}$ ) divided according to stoichiometry and the number of neighboring $\mathrm{C}-\mathrm{F}$ bonds.

\begin{tabular}{c|c|c|}
\multicolumn{3}{|c}{ Number of neighboring } \\
Stoichiometry & F ad-atoms & $R^{2}$ \\
\hline $\mathrm{C}_{32} \mathrm{~F}_{2}$ & 0 & 0.543 \\
$\mathrm{C}_{32} \mathrm{~F}_{3}$ & 0 & 0.402 \\
$\mathrm{C}_{32} \mathrm{~F}_{4}$ & 0 & 0.537 \\
$\mathrm{C}_{32} \mathrm{~F}_{3}$ & 1 & 0.601 \\
\cline { 2 - 3 } $\mathrm{C}_{32} \mathrm{~F}_{4}$ & 1 & 0.683 \\
$\mathrm{C}_{32} \mathrm{~F}_{5}$ & 1 & 0.946 \\
$\mathrm{C}_{32} \mathrm{~F}_{3}$ & 2 & 0.979 \\
$\mathrm{C}_{32} \mathrm{~F}_{4}$ & 2 & 0.919 \\
$\mathrm{C}_{32} \mathrm{~F}_{5}$ & 2 & 0.939 \\
$\mathrm{C}_{32} \mathrm{~F}_{6}$ & 2 & 0.973 \\
$\mathrm{C}_{32} \mathrm{~F}_{4}$ & 3 & 0.972 \\
\hline
\end{tabular}

On the other hand, all variables do not co-vary only with BDE but also with each other (Table S2). Therefore, we have carried out also multiple regressions. Results showed (Table S3) that the C-F bond length significantly correlates with $\operatorname{BDE}\left(R^{2}=0.530\right)$ but the polarity of the C-F bond as an additional parameter does not significantly affect the value of $R^{2}\left(R^{2}=0.531\right)$. On the other hand, $\pi$-conjugation is more significant $\left(R^{2}=0.58\right)$. The most significant considered predictor is the 
number of adjoining fluorine ad-atoms in trans position $\left(R^{2}=0.72\right)$. Standard error of the estimate of BDE shows that $95 \%$ of observations will fall within the interval of $\pm 9.11 \mathrm{kcal} / \mathrm{mol}$.

Table S2: Pearson correlation coefficients of five C-F bond descriptors (C-F bond dissociation energy in $\mathrm{kcal} \cdot \mathrm{mol}^{-1}, \mathrm{C}-\mathrm{F}$ bond length in $\AA$, polarity of $\mathrm{C}$-F bond in $e, \pi$-conjugation and number of adjoining fluorine ad-atoms in trans position).

\begin{tabular}{|c|c|c|c|c|c|}
\hline $\begin{array}{c}\text { Pearson } \\
\text { Correlation }\end{array}$ & BDE & $\begin{array}{l}\text { C-F bond } \\
\text { length }\end{array}$ & $\begin{array}{l}\text { C-F bond } \\
\text { polarity }\end{array}$ & $\pi$-conjugation & $\begin{array}{l}\text { fluorine ad- } \\
\text { atoms in trans } \\
\text { position }\end{array}$ \\
\hline$B D E$ & 1.000 & -0.728 & 0.566 & -0.737 & 0.747 \\
\hline $\begin{array}{r}C-F \text { bond } \\
\text { length }\end{array}$ & -0.728 & 1.000 & -0.754 & 0.862 & -0.505 \\
\hline $\begin{array}{r}C-F \text { bond } \\
\text { polarity }\end{array}$ & 0.566 & -0.754 & 1.000 & -0.738 & 0.447 \\
\hline$\pi$-conjugation & -0.737 & 0.862 & -0.738 & 1.000 & -0.655 \\
\hline $\begin{array}{r}\text { fluorine ad- } \\
\text { atoms in trans } \\
\text { position }\end{array}$ & 0.747 & -0.505 & 0.477 & -0.655 & 1.000 \\
\hline
\end{tabular}

Table S3. Multiple regression of BDE in $\mathrm{kcal} \cdot \mathrm{mol}^{-1}$ with four $\mathrm{C}-\mathrm{F}$ bond descriptors that have the biggest value of multiple correlation coefficient (C-F bond length in $\AA$, polarity of C-F bond in $e$, $\pi$-conjugation, number of adjoining fluorine ad-atoms in trans position).

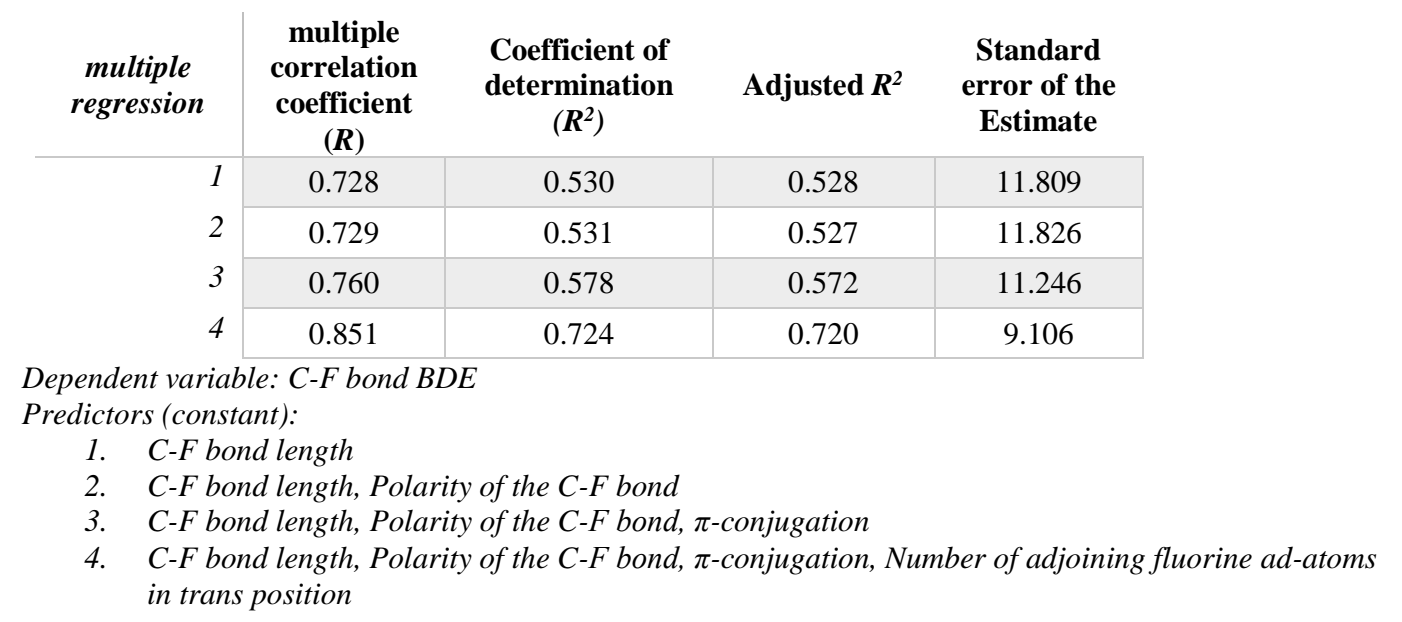

However, in practice it is not very useful to estimate BDE (and thus the stability of pFGs) by the C-F bond length because it also requires performing quantum chemistry calculations. Therefore, Table $\mathbf{S 4}$ shows multiple regression of BDE with two topological descriptors $-\pi$-conjugation and the number of adjoining fluorine ad-atoms in trans position. Coefficient of determination is in this 
case $R^{2}=0.67$. The standard error of the estimate shows that $95 \%$ of observations will fall within the interval of $\pm 9.98 \mathrm{kcal} / \mathrm{mol}$.

Table S4. Multiple regression of $\mathrm{C}-\mathrm{F}$ bond BDE in $\mathrm{kcal} \cdot \mathrm{mol}^{-1}$ with two topological descriptors $(\pi$ conjugation and the number of adjoining fluorine ad-atoms in trans position).

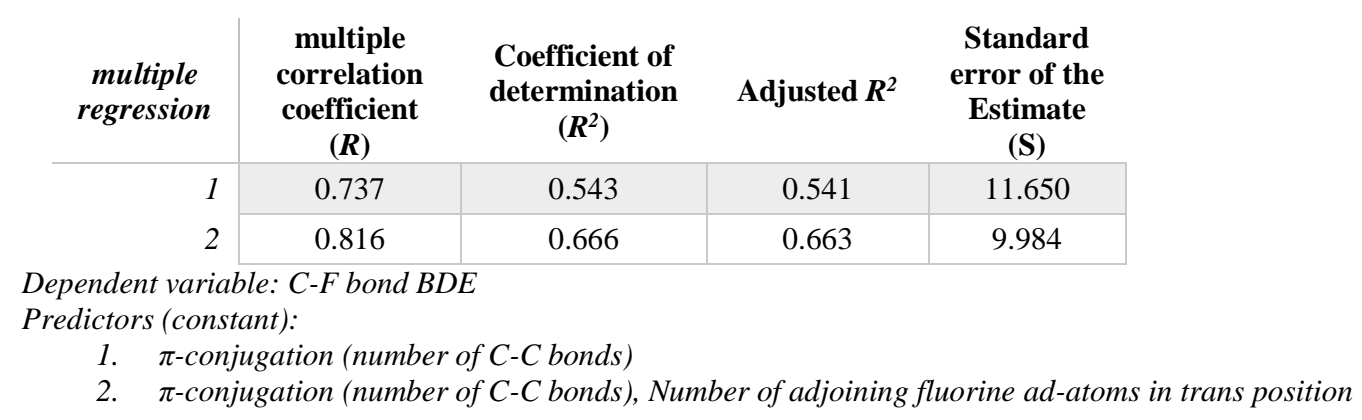

Multiple regression also indicates that BDE depends on these two topological parameters according to equation:

$$
B D E=(68.640 \pm 5.016)-\left[(8.873 \pm 2.005) * N_{\pi}\right]+\left[(10.925 \pm 2.307) * N_{F \text { trans }}\right]
$$

where $N_{\pi}$ is the $\pi$-conjugation and $N_{F}$ trans is the number of adjoining fluorine ad-atoms in trans position (with error of 2.005 for $\pi$-conjugation and 2.307 for number of fluorine ad-atoms in trans position within $95 \%$ confidence interval).

\section{Relative stability of pFGs structures}

To evaluate the possibility of formation of various structural motifs on graphene, we calculated the Boltzmann probability of structures at $293 \mathrm{~K}, 400 \mathrm{~K}$ and $600 \mathrm{~K}$ as follows:

$$
p_{i}=\frac{e^{-\frac{E_{i}^{T}}{k_{B} T}}}{Q},
$$

where the partition function $Q$ is expressed as:

$$
Q=\sum_{j} e^{-\frac{E_{j}^{T}}{k_{B} T}}
$$


where $p_{i}$ is the probability of the $i$-th configuration, $E_{i}^{T}$ is the total energy per computational cell, the summation runs over all considered configurations, $k_{B}$ is the Boltzmann constant and $T$ is thermodynamic temperature $(293 \mathrm{~K}, 400 \mathrm{~K}$ and $600 \mathrm{~K})$.
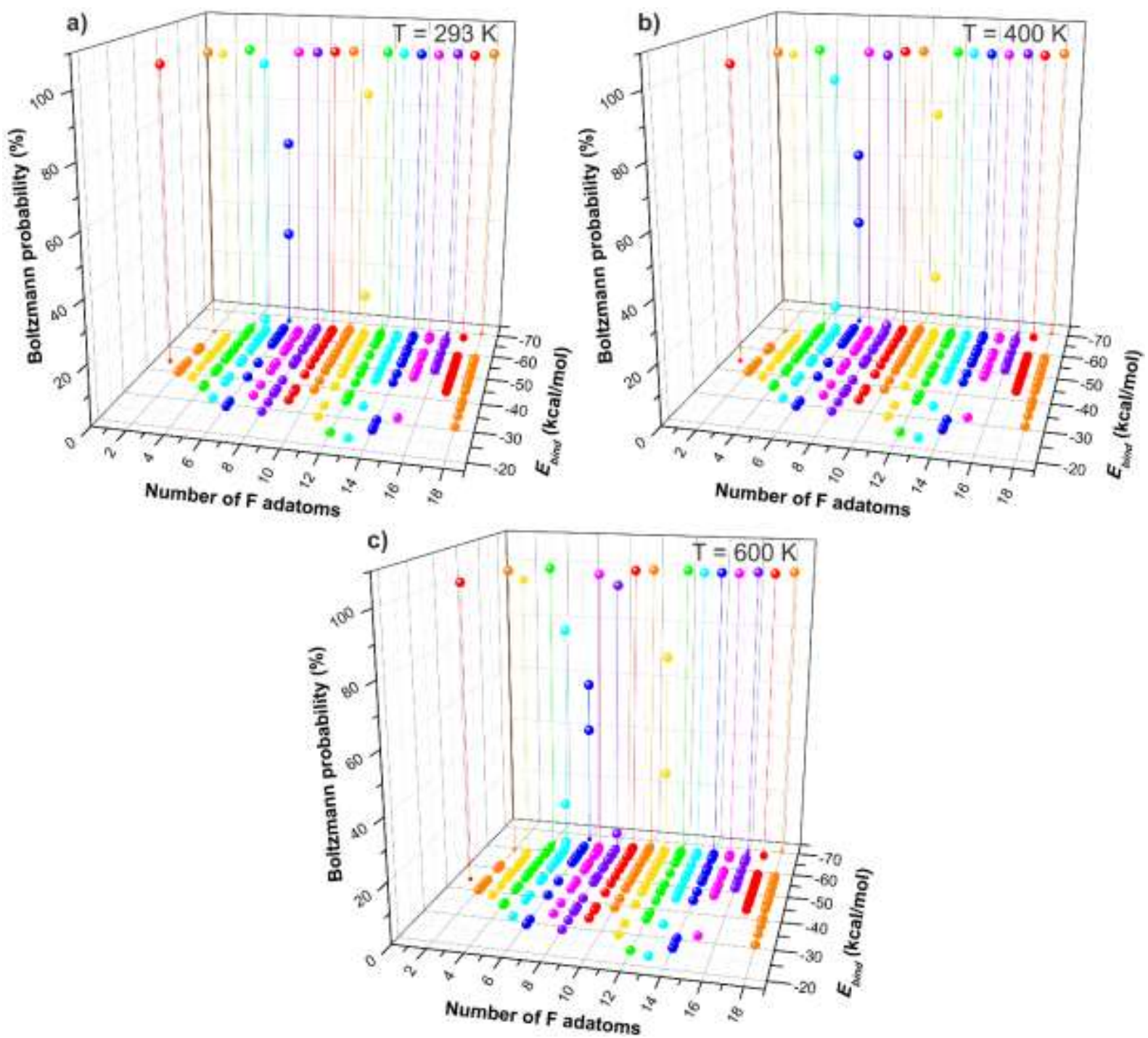

Figure S7. Boltzmann distribution and binding energies of $\mathrm{C}_{18} \mathrm{~F}_{\mathrm{x}}$ structures $(\mathrm{x}=1-18)$ at (a) 293 $\mathrm{K}$, (b) $400 \mathrm{~K}$ and (c) $600 \mathrm{~K}$.

\section{Fluorination}

Figure 2 in the main text shows that the stability of partially fluorinated graphene depends on the stoichiometry and configuration of $\mathrm{F}$ ad-atoms on the graphene lattice. The structures shown in Figures S8-S21 were obtained by gradual fluorination of graphene lattice. It is a complex process in which the GS of higher coverage is not always created from the most stable configuration with 
one less fluorine ad-atom. In general, fluorine ad-atoms prefer to grow in lines (armchair or zigzag); the formation of hexagonal rings is also favorable. The stability of the ground-state pFGs increases with the higher $\mathrm{F} / \mathrm{C}$ ratio and oscillates between even/odd numbers of $\mathrm{F}$ ad-atoms. The GS structures with even number of ad-atoms are non-magnetic and more stable than those with odd number of $\mathrm{F}$ ad-atoms and magnetic. One shall note, however, that the GS and higher-inenergy structures are close in energy.

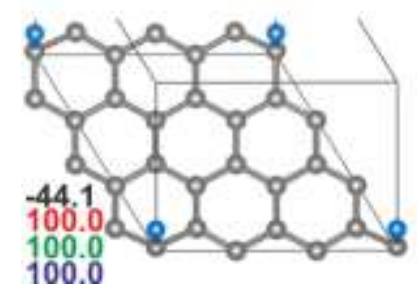

Figure S8. Optimized lowest-in-energy structures of $\mathrm{C}_{18} \mathrm{~F}_{1}$. Carbon atoms in grey, fluorine adatoms in blue. Numbers refer to binding energies per fluorine ad-atom (kcal/mol) (black) and Boltzmann probability at $293 \mathrm{~K}$ (red), $400 \mathrm{~K}$ (green) and $600 \mathrm{~K}$ (blue).
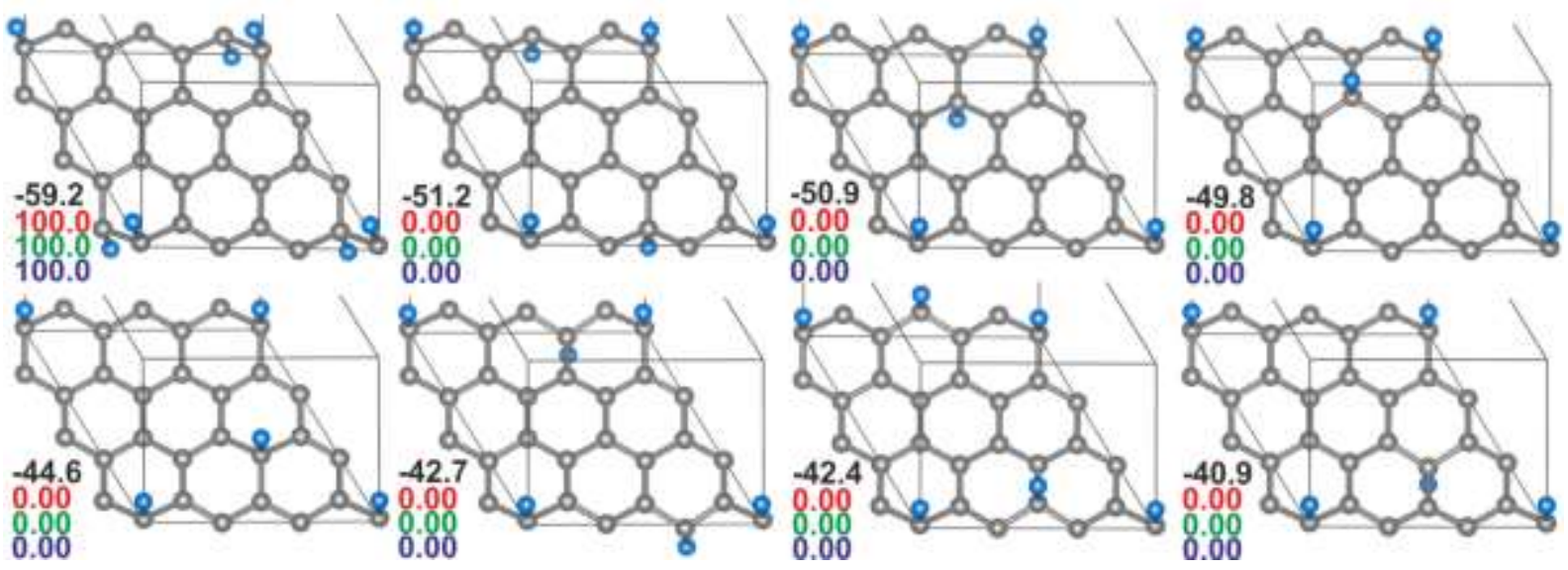

Figure S9. Optimized lowest-in-energy structures of $\mathrm{C}_{18} \mathrm{~F}_{2}$. CF., Figure S8. 

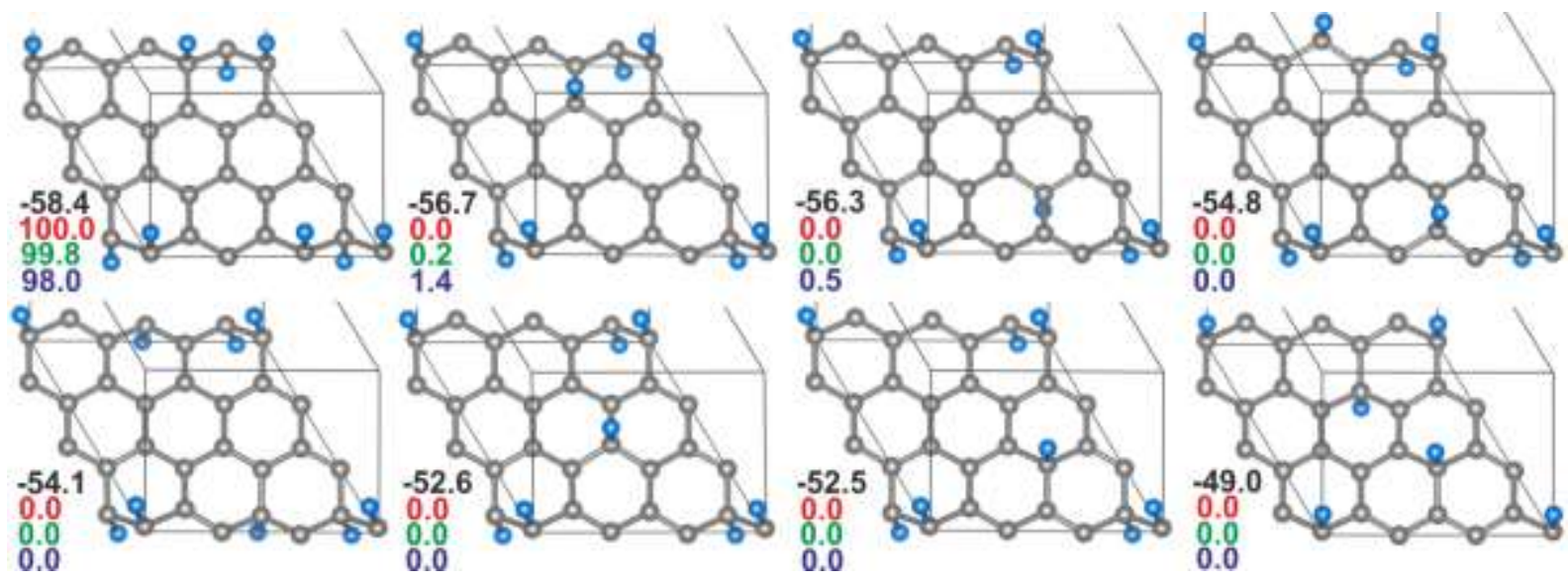

Figure S10. Optimized lowest-in-energy structures of $\mathrm{C}_{18} \mathrm{~F}_{3}$. CF., Figure S8.
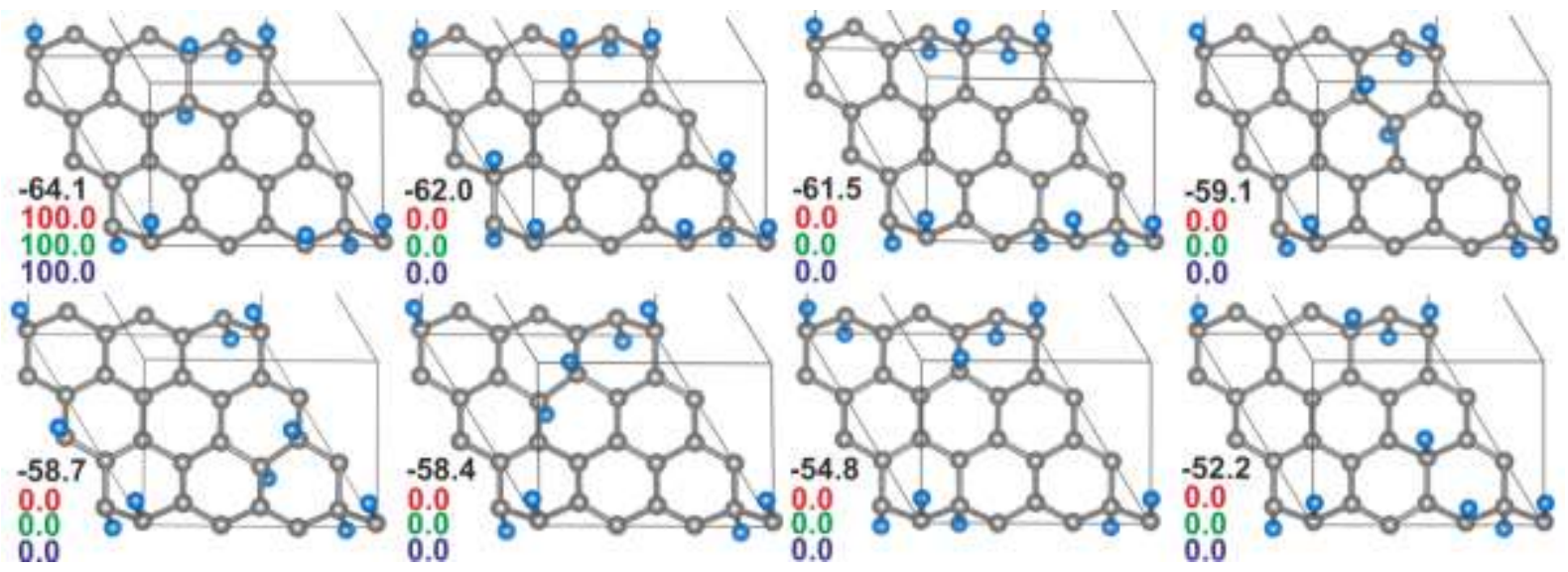

Figure S11. Optimized lowest-in-energy structures of $\mathrm{C}_{18} \mathrm{~F}_{4}$. CF., Figure S8.
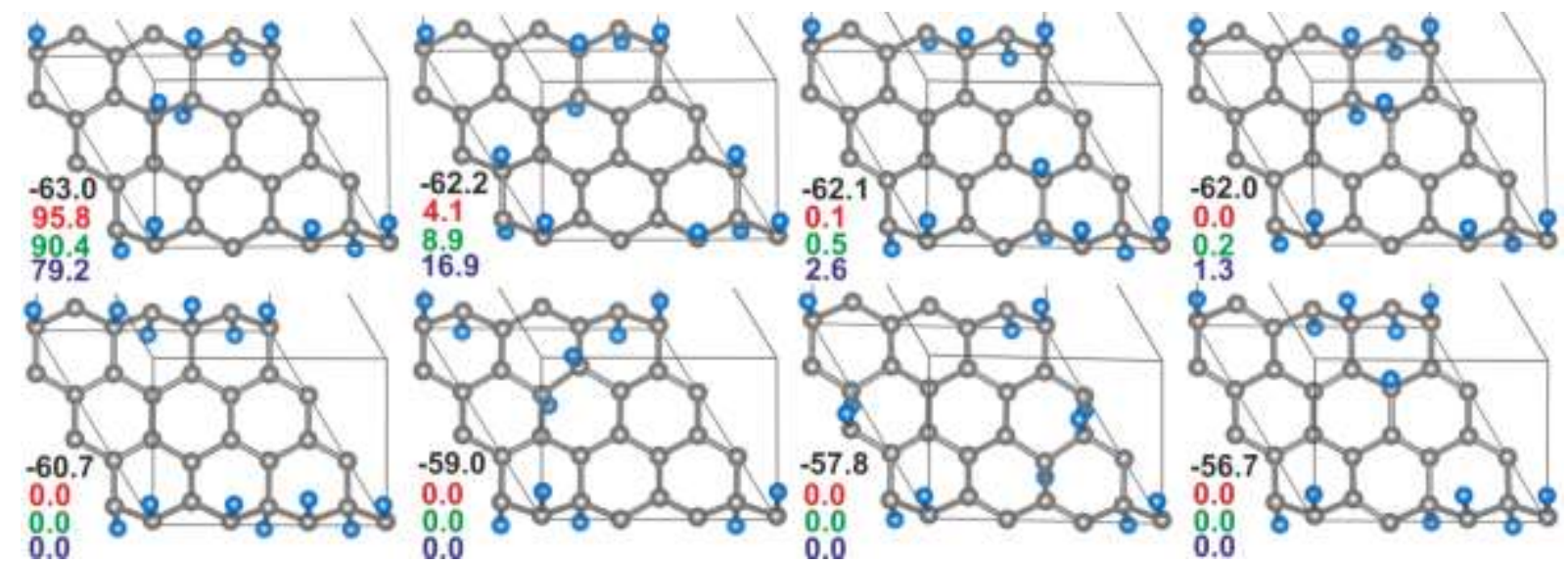

Figure S12. Optimized lowest-in-energy structures of $\mathrm{C}_{18} \mathrm{~F}_{5}$. CF., Figure S8. 

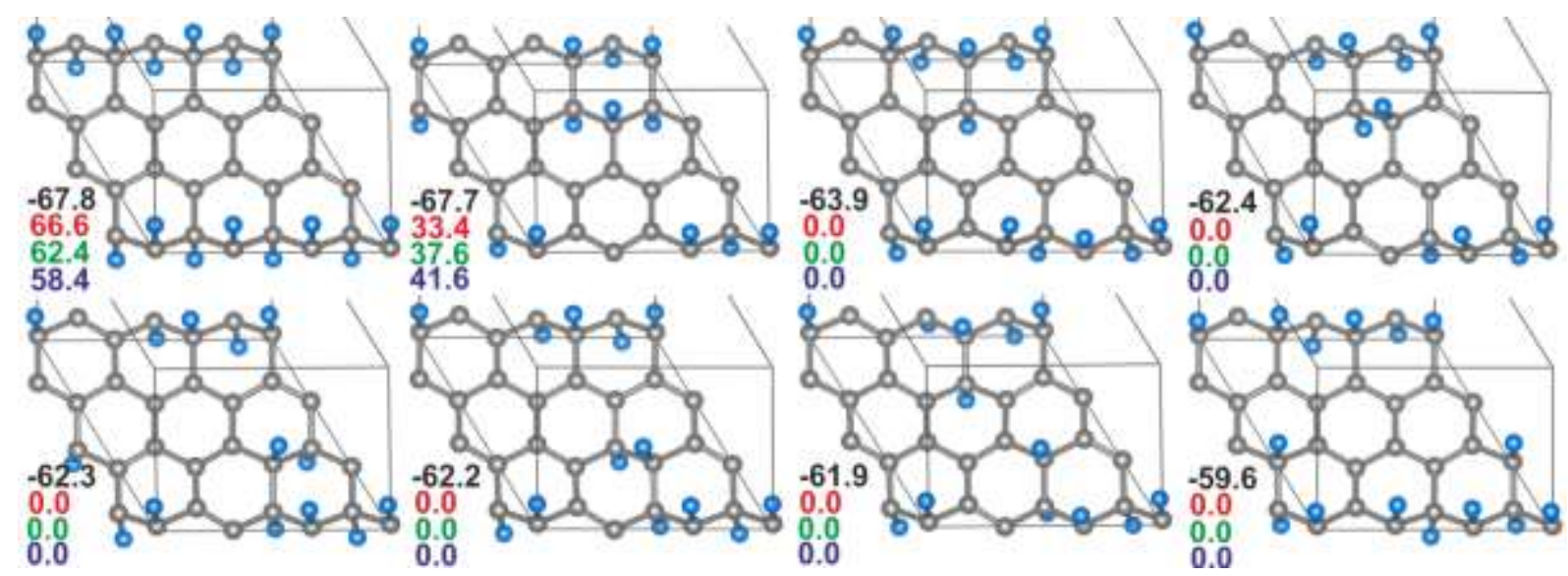

Figure S13. Optimized lowest-in-energy structures of $\mathrm{C}_{18} \mathrm{~F}_{6}$. CF., Figure S8.
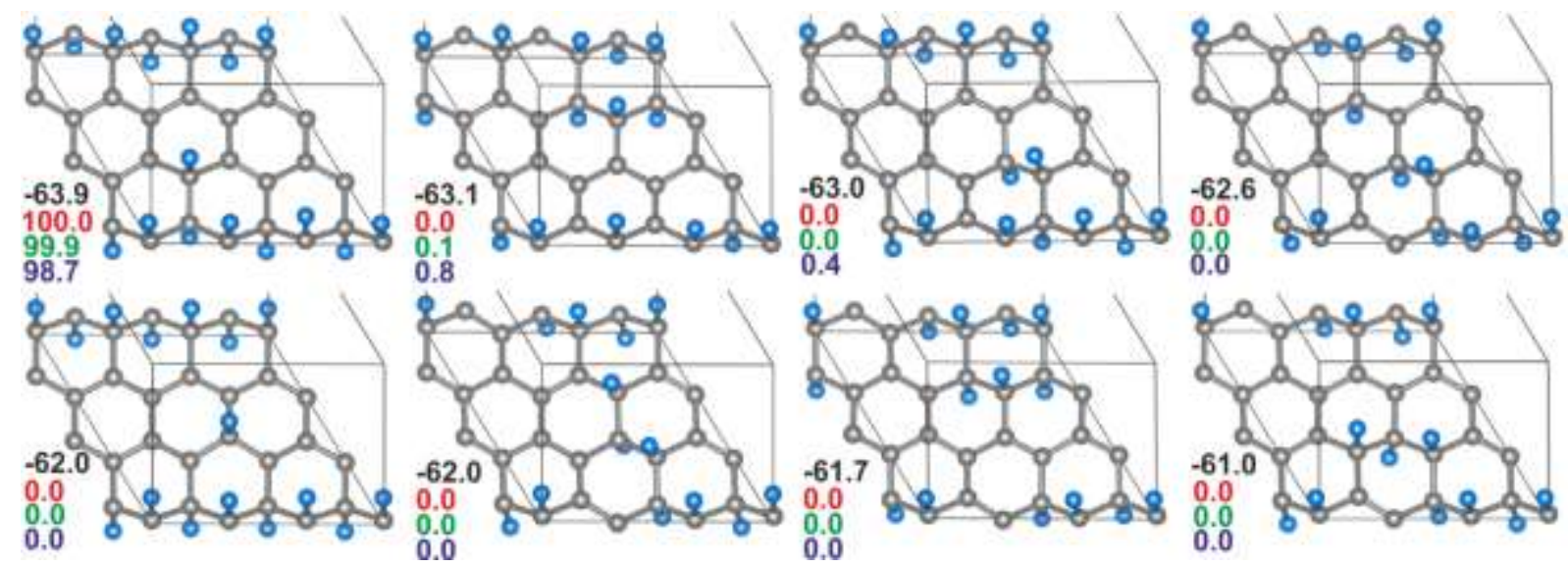

Figure S14. Optimized lowest-in-energy structures of $\mathrm{C}_{18} \mathrm{~F}_{7}$. CF., Figure S8.
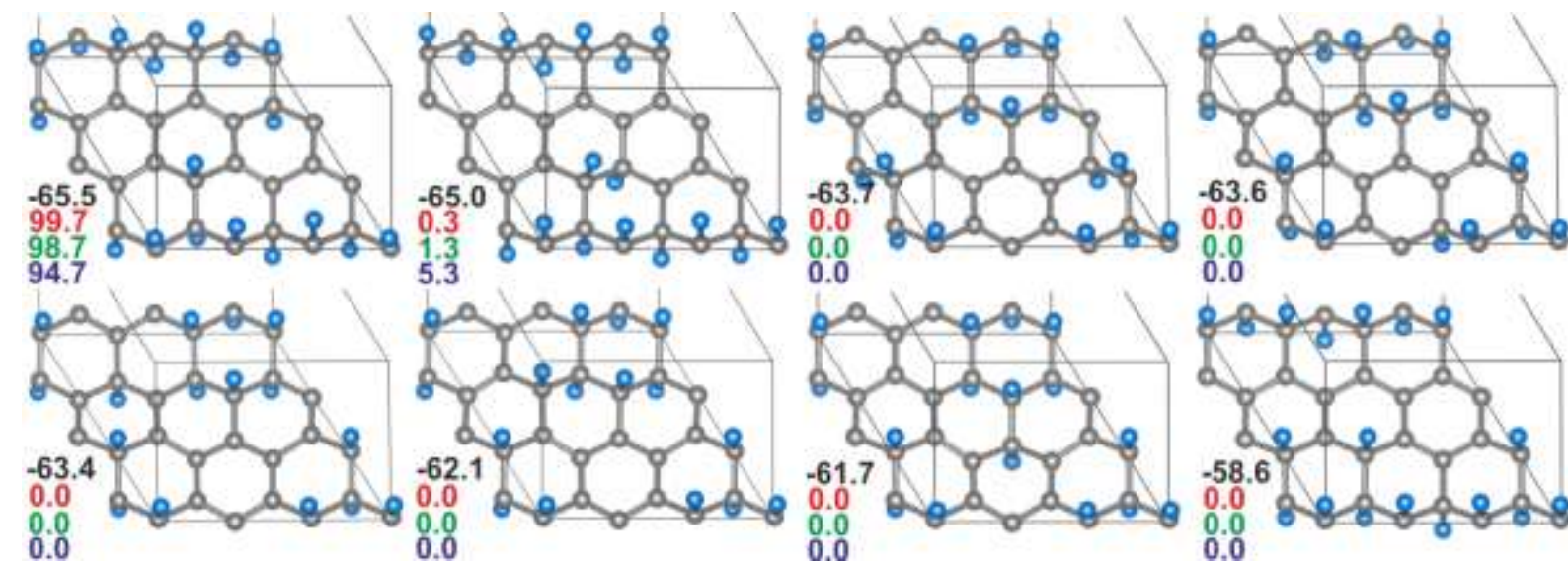

Figure S15. Optimized lowest-in-energy structures of $\mathrm{C}_{18} \mathrm{~F}_{8}$. CF., Figure S8.
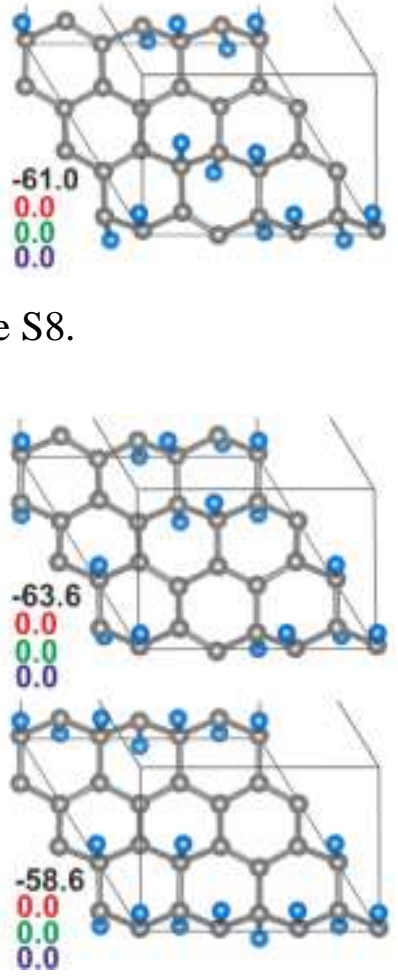

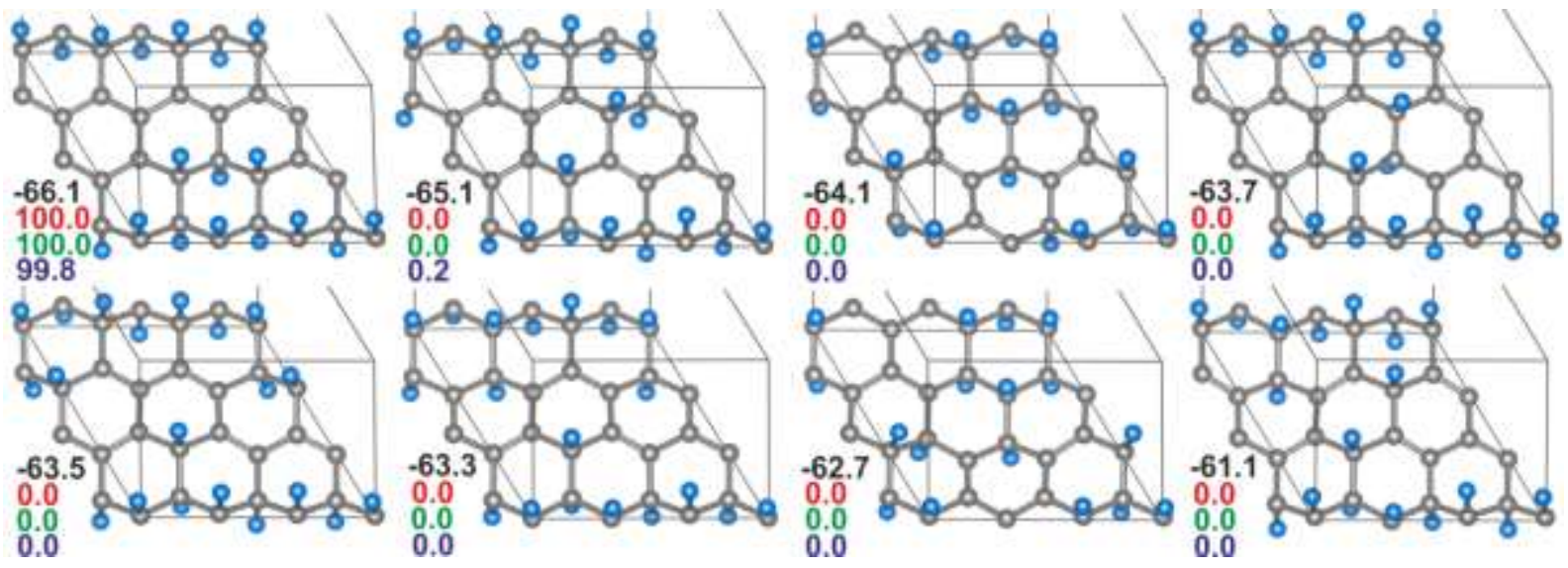

Figure S16. Optimized lowest-in-energy structures of $\mathrm{C}_{18} \mathrm{~F}_{9}$. CF., Figure S8.
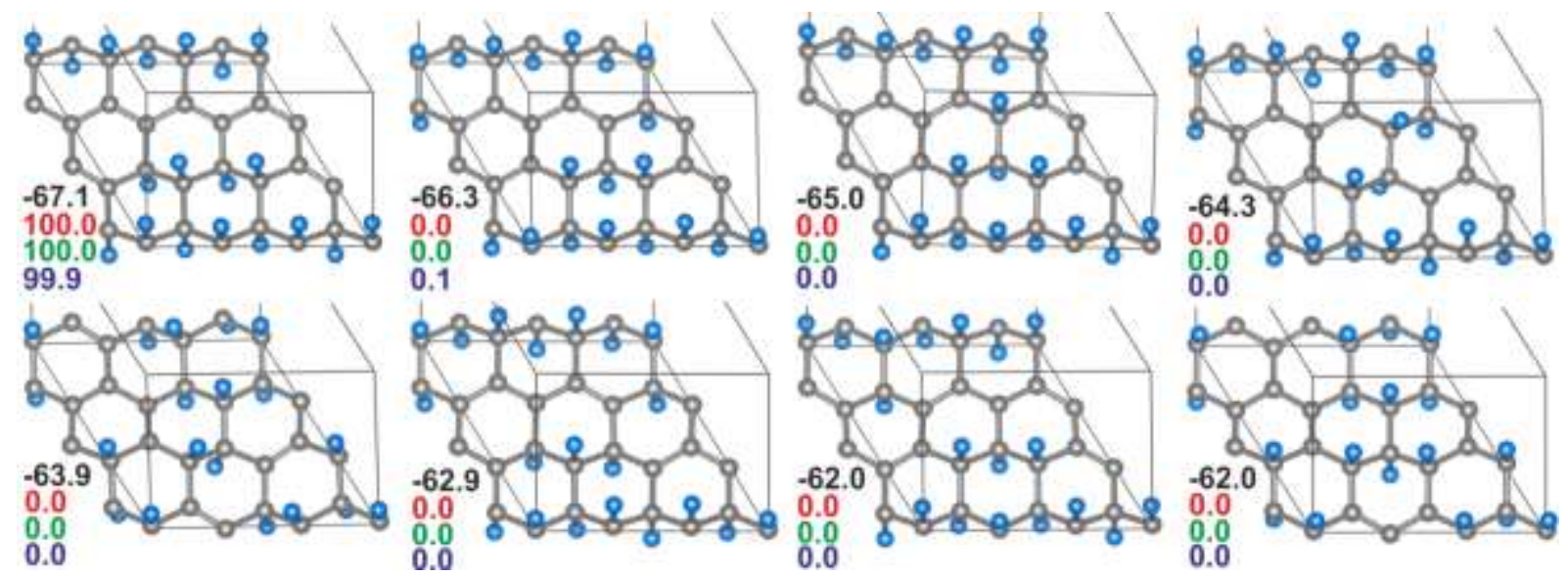

Figure S17. Optimized lowest-in-energy structures of $\mathrm{C}_{18} \mathrm{~F}_{10}$. CF., Figure S8.
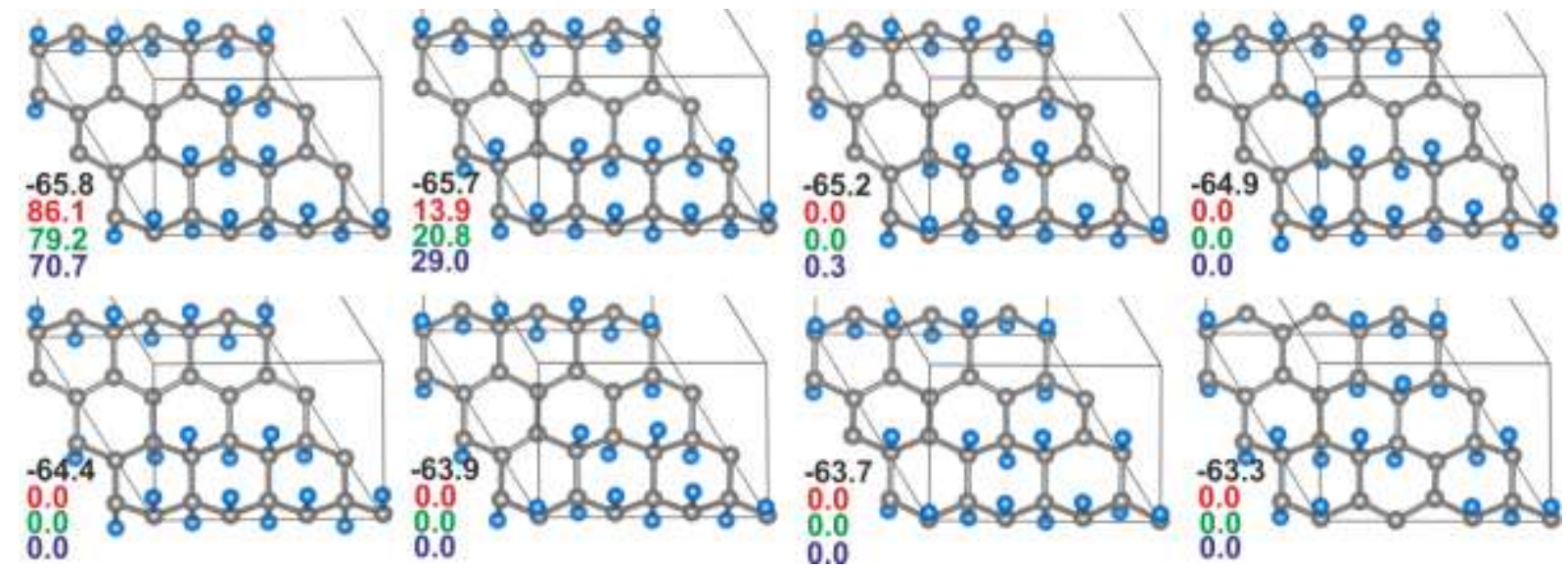

Figure S18. Optimized lowest-in-energy structures of $\mathrm{C}_{18} \mathrm{~F}_{11}$. CF., Figure S8. 

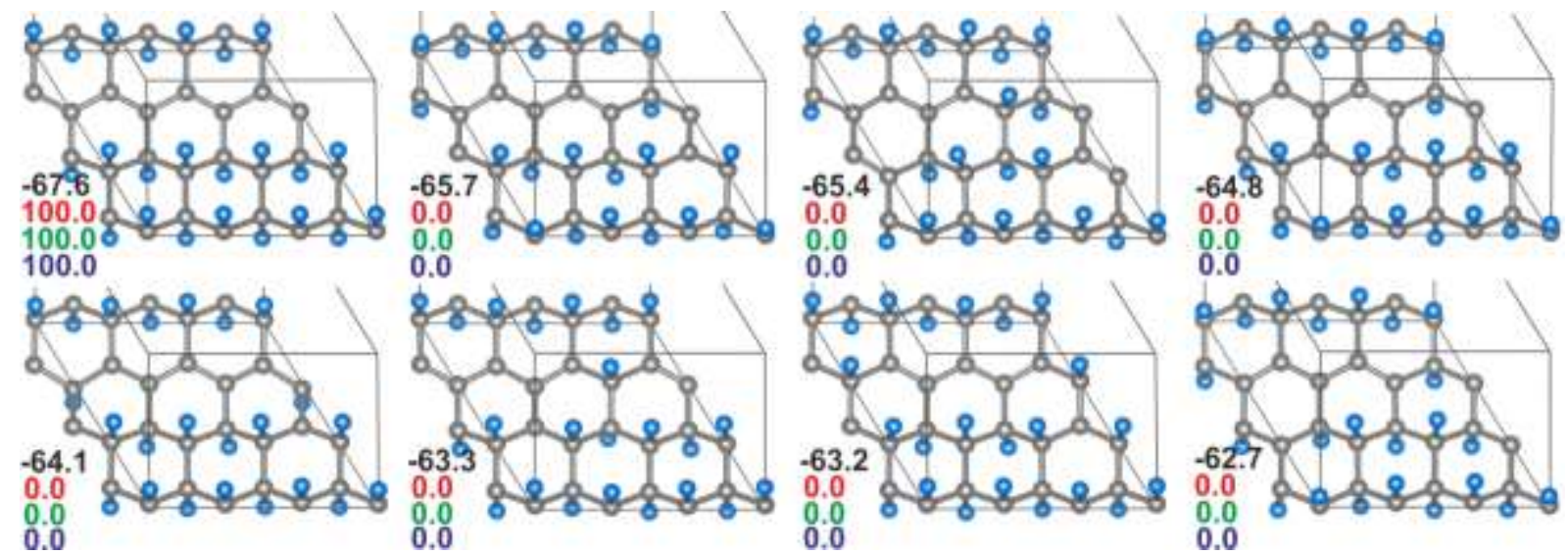

Figure S19. Optimized lowest-in-energy structures of $\mathrm{C}_{18} \mathrm{~F}_{12}$. CF., Figure S8.

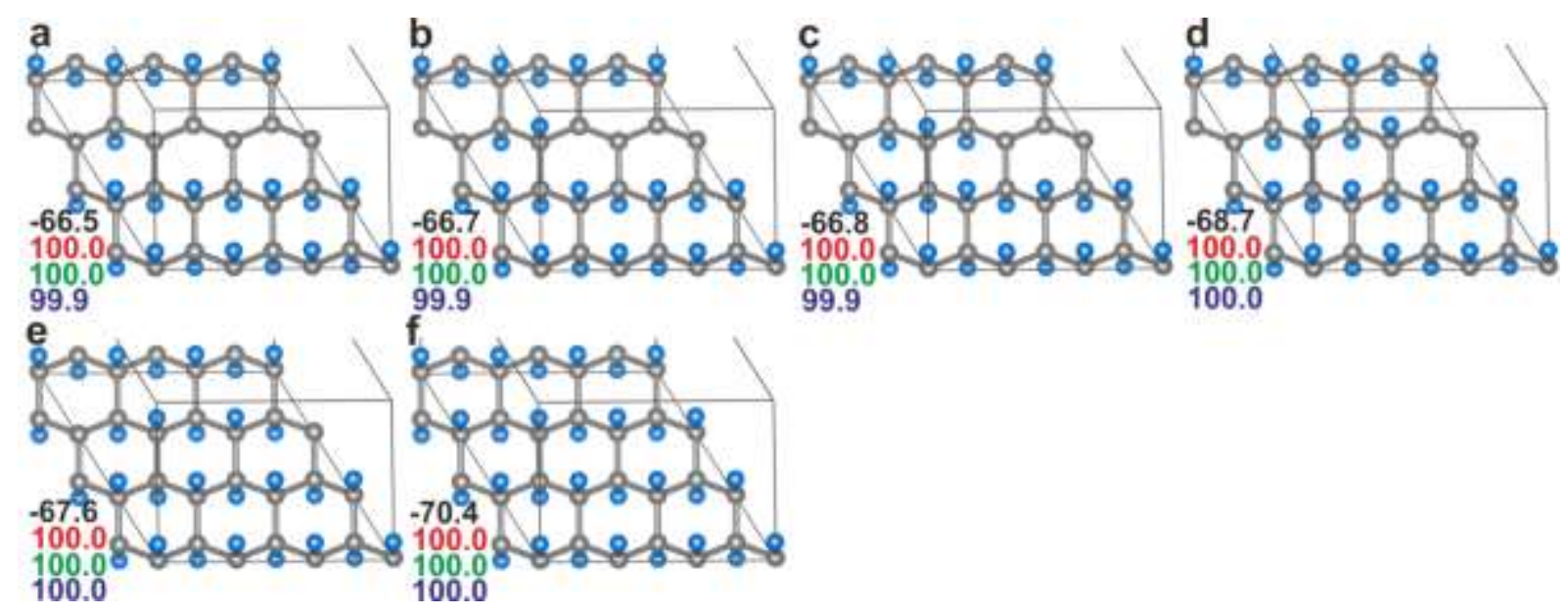

Figure S20. Optimized lowest-in-energy structures of (a) $\mathrm{C}_{18} \mathrm{~F}_{13}$, (b) $\mathrm{C}_{18} \mathrm{~F}_{14}$, (c) $\mathrm{C}_{18} \mathrm{~F}_{15}$, (d) $\mathrm{C}_{18} \mathrm{~F}_{16}$, (e) $\mathrm{C}_{18} \mathrm{~F}_{17}$, (f) $\mathrm{C}_{18} \mathrm{~F}_{18}$. CF., Figure $\mathrm{S} 8$. 


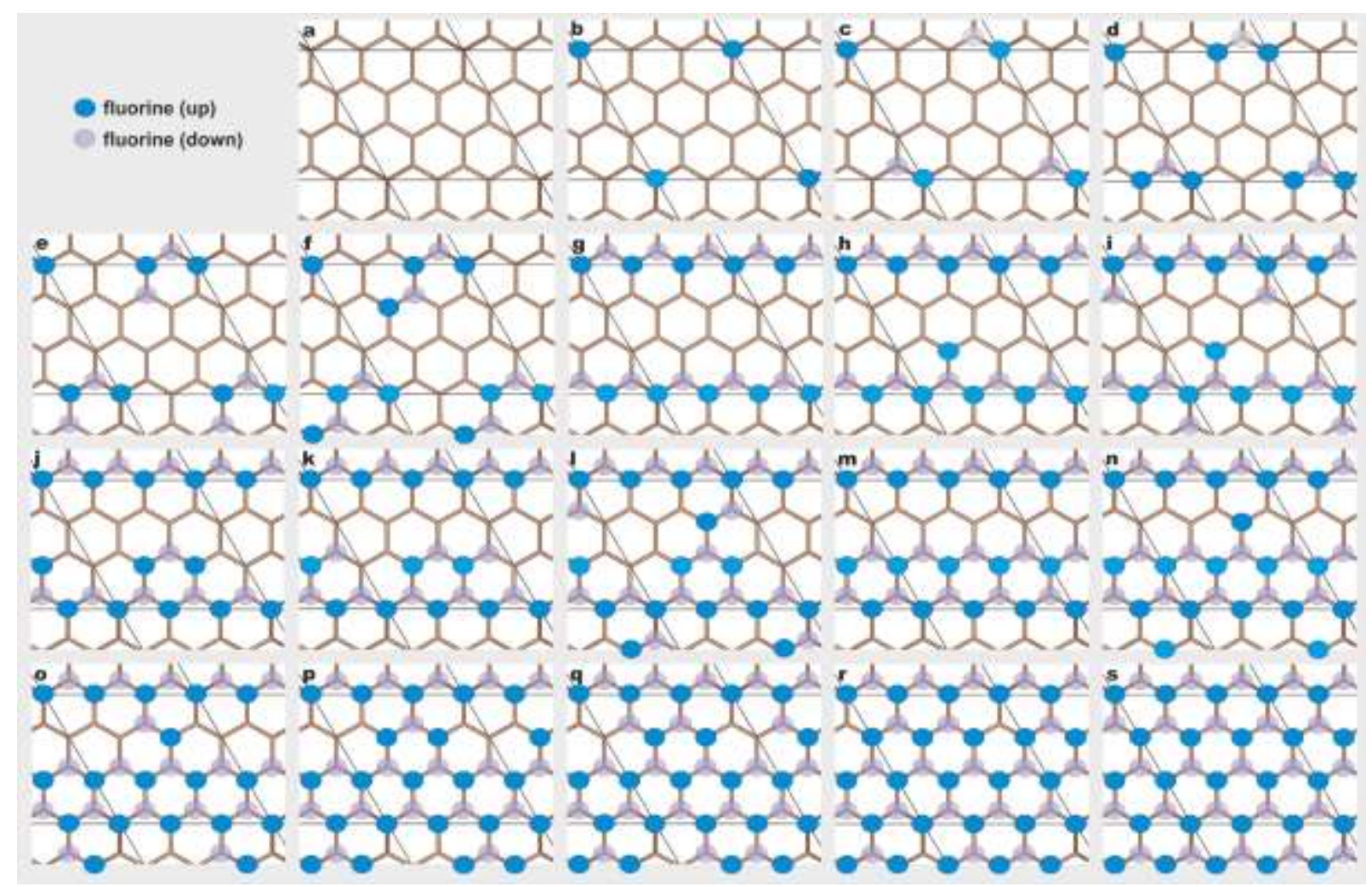

Figure S21. The most stable patterns of (p)FGs with different stoichiometry: a) $\mathrm{C}_{18}$, b) $\mathrm{C}_{18} \mathrm{~F}_{1}$, c) $\mathrm{C}_{18} \mathrm{~F}_{2}$, d) $\mathrm{C}_{18} \mathrm{~F}_{3}$, e) $\mathrm{C}_{18} \mathrm{~F}_{4}$, f) $\mathrm{C}_{18} \mathrm{~F}_{5}$, g) $\mathrm{C}_{18} \mathrm{~F}_{6}$, h) $\mathrm{C}_{18} \mathrm{~F}_{7}$, i) $\mathrm{C}_{18} \mathrm{~F}_{8}$, j) $\mathrm{C}_{18} \mathrm{~F}_{9}$, k) $\mathrm{C}_{18} \mathrm{~F}_{10}$, l) $\mathrm{C}_{18} \mathrm{~F}_{11}$, m) $\mathrm{C}_{18} \mathrm{~F}_{12}$, n) $\mathrm{C}_{18} \mathrm{~F}_{13}$, o) $\mathrm{C}_{18} \mathrm{~F}_{14}$, p) $\mathrm{C}_{18} \mathrm{~F}_{15}$, q) $\mathrm{C}_{18} \mathrm{~F}_{16}$, r) $\mathrm{C}_{18} \mathrm{~F}_{17}$, s) $\mathrm{C}_{18} \mathrm{~F}_{18}$. Fluorine ad-atoms are illustrated as blue circles or light blue circles with a cross to distinguish fluorine ad-atoms bonded on different sides of graphene.

The preferable formation of zigzag lines could be biased by the size of $\mathrm{C}_{18}$-cell, where the lines are infinite already for six fluorine ad-atoms. Therefore, we also used a larger cell $\left(\mathrm{C}_{72}\right)$ with up to six fluorine ad-atoms. The fluorine ad-atoms follow the same fluorination path except $\mathrm{C}_{72} \mathrm{~F}_{6}$ where the branched zigzag and armchair lines are combined (Figure S22). 
a

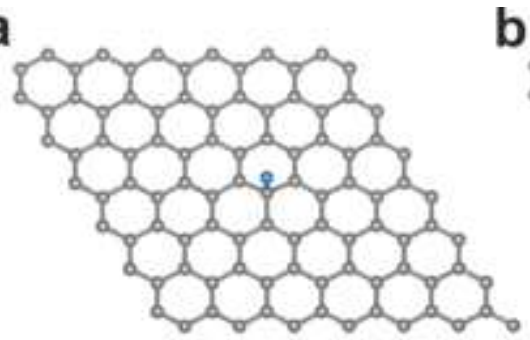

d

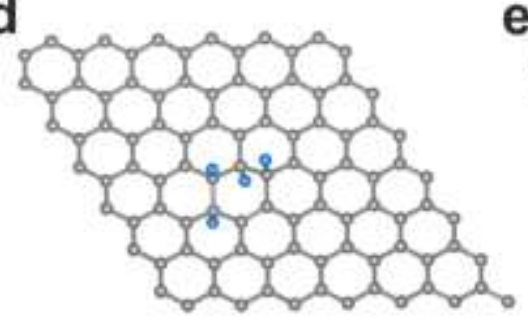

b

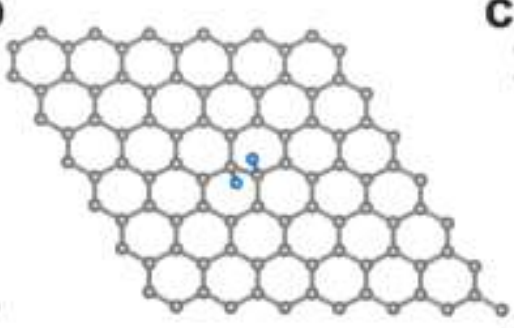

e

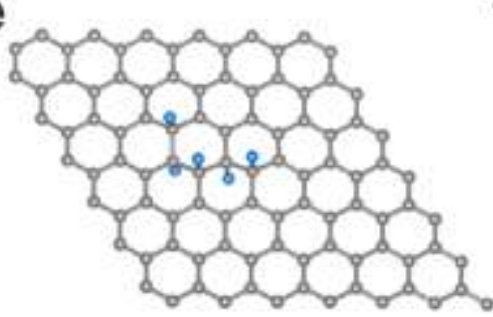

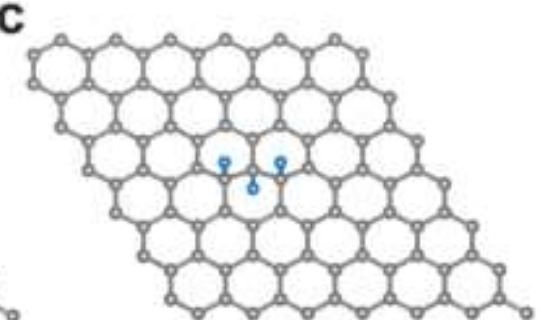

f

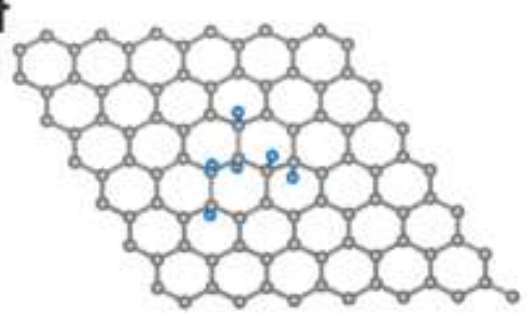

Figure S22. The most stable patterns of fluorographene systems with different stoichiometry:

a) $\mathrm{C}_{72} \mathrm{~F}_{1}$, b) $\mathrm{C}_{72} \mathrm{~F}_{2}$, c) $\mathrm{C}_{72} \mathrm{~F}_{3}$, d) $\mathrm{C}_{72} \mathrm{~F}_{4}$, e) $\mathrm{C}_{72} \mathrm{~F}_{5}$, f) $\mathrm{C}_{72} \mathrm{~F}_{6}$. Carbon atoms in grey, fluorine ad-atoms in blue.

\section{Defluorination}

To study defluorination of FG, we applied the reverse procedure to fluorination (Figure S23). First, one $\mathrm{F}$ ad-atom was removed from $\mathrm{FG}$. Next, several configurations of $\mathrm{C}_{18} \mathrm{~F}_{16}$ were created by removal of one of a fluorine ad-atom from $\mathrm{C}_{18} \mathrm{~F}_{17}$. This process was repeated up to $\mathrm{C}_{18} \mathrm{~F}_{12}$.

a

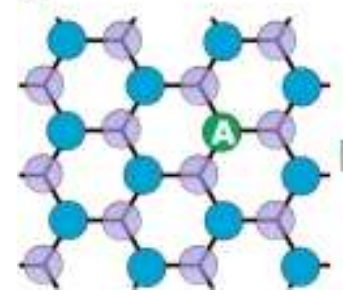

b

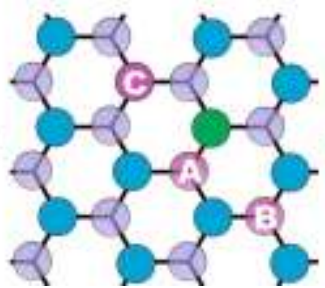

C

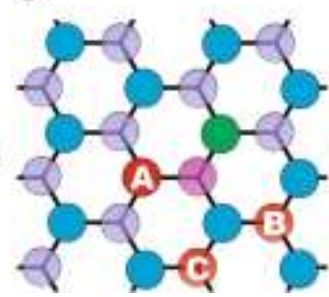

d

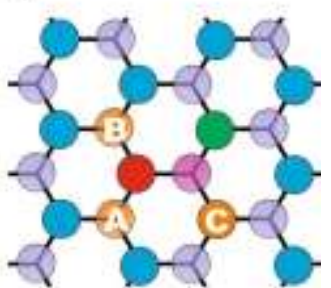

Figure S23. The defluorination procedure of FG. Green, violet, red and orange circles denote removed $\mathrm{F}$ ad-atoms. The notation $\mathrm{A}, \mathrm{B}, \mathrm{C}$ corresponds to a stability trend with $\mathrm{A}$ being the most stable $\mathrm{C}_{18} \mathrm{~F}_{\mathrm{X}-1}$ structure after removal of the $\mathrm{F}$ ad-atom. $\mathrm{F}$ ad-atoms are illustrated as blue circles or grey circles with a cross to distinguish fluorine ad-atoms bonded on opposite sides of graphene.

Defluorination of FG preferentially proceeds along the $s p^{2}$ zigzag lines (Figure 3g) rather than along other $s p^{2}$ motifs such as hexagonal rings or armchair lines (Figure S24). 


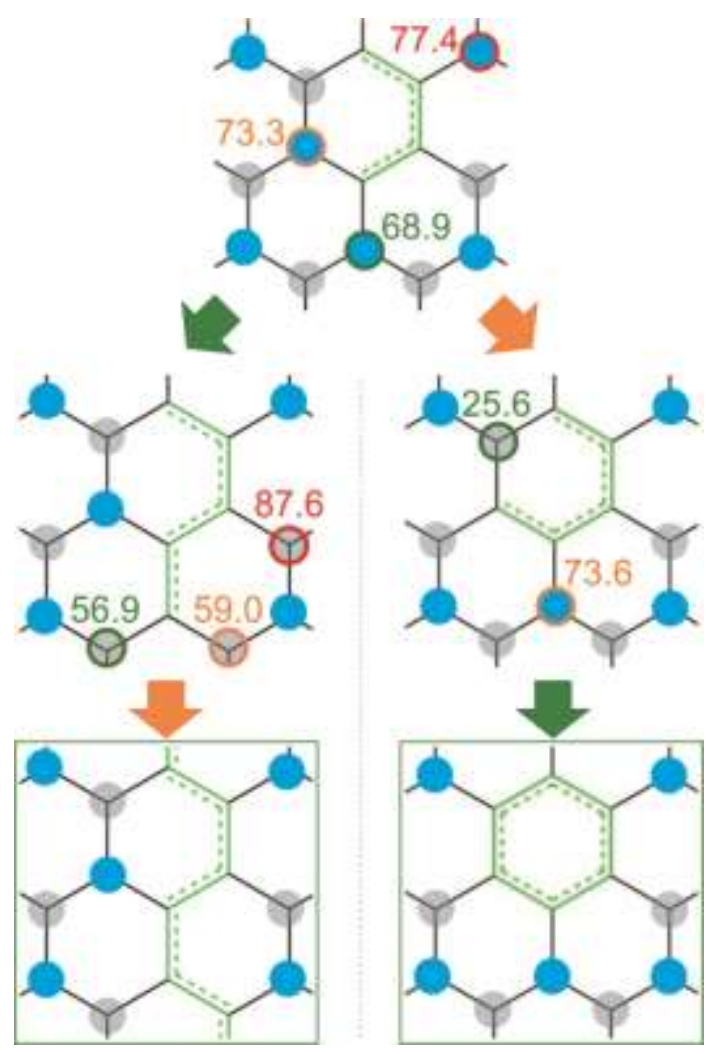

Figure S24. Defluorination of $\mathrm{pFGs}$ leading to the formation of $s p^{2}$ armchair lines or $s p^{2}$ hexagons. The numbers correspond to $\mathrm{BDE}\left(\mathrm{kcal} \cdot \mathrm{mol}^{-1}\right)$; colors refer the feasibility of the removal of an $\mathrm{F}$ ad-atom. 


\section{Electronic and magnetic properties}

The band-gap width of pFGs generally increases with the number of $\mathrm{F}$ ad-atoms (Figure S25a). Larger gaps resulted in higher energy difference between ferromagnetic and non-magnetic phases, $\Delta E_{F M-N M}$, which is associated with higher transition temperatures (Figure $\mathbf{2 5} \mathbf{b}$ ).
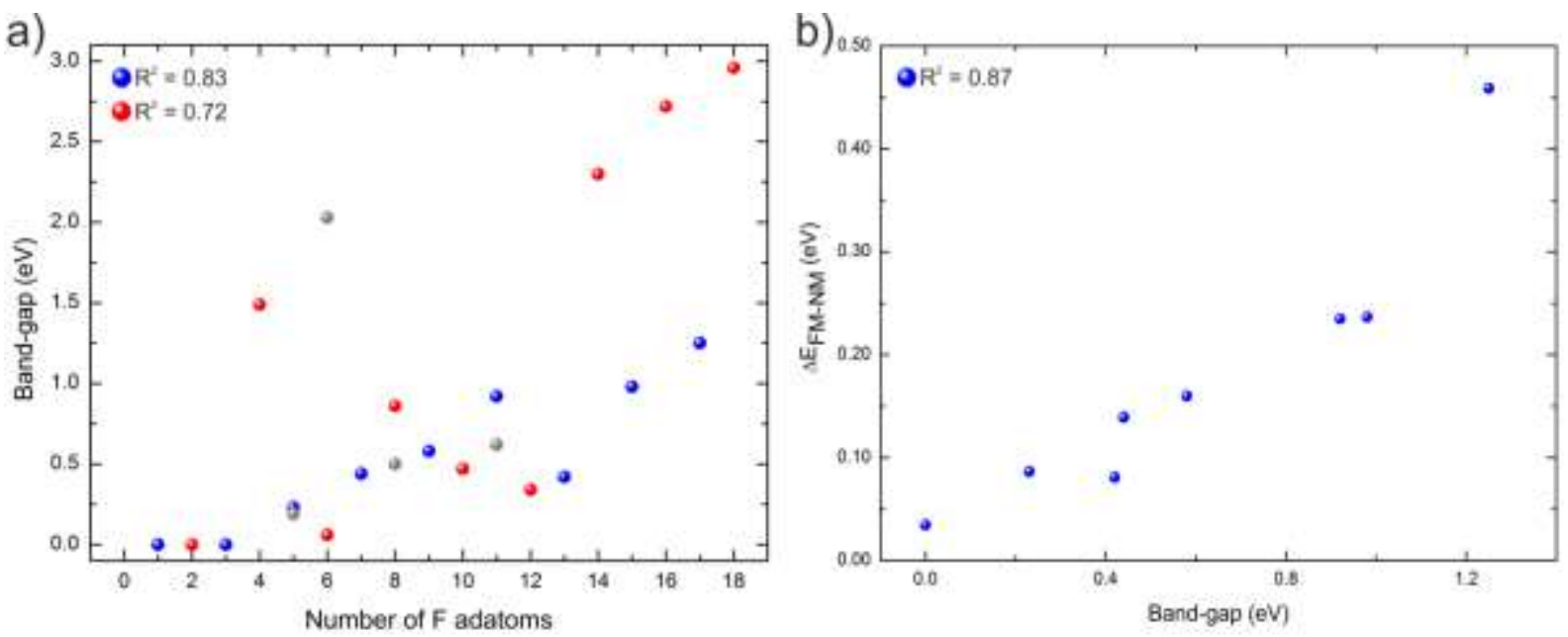

Figure S25. The band-gaps of pFGs in the GS vs. number of F ad-atoms. Structures with odd number of ad-atoms (blue points) are magnetic except $\mathrm{C}_{18} \mathrm{~F}_{1}$ which is non-magnetic, all structures with even number of ad-atoms (red points) are non-magnetic. The grey points correspond to selected less stable structures with non-zero Boltzmann probabilities (Figure S7). b) $\Delta E_{F M-N M}$ (per computational cell) as a function of band-gaps' width. Since $\Delta E_{F M-N M}$ is proportionally related to the $J$ exchange integral and also to the transition temperature, wider band-gap of magnetic pFGs corresponds to higher transition temperature. 


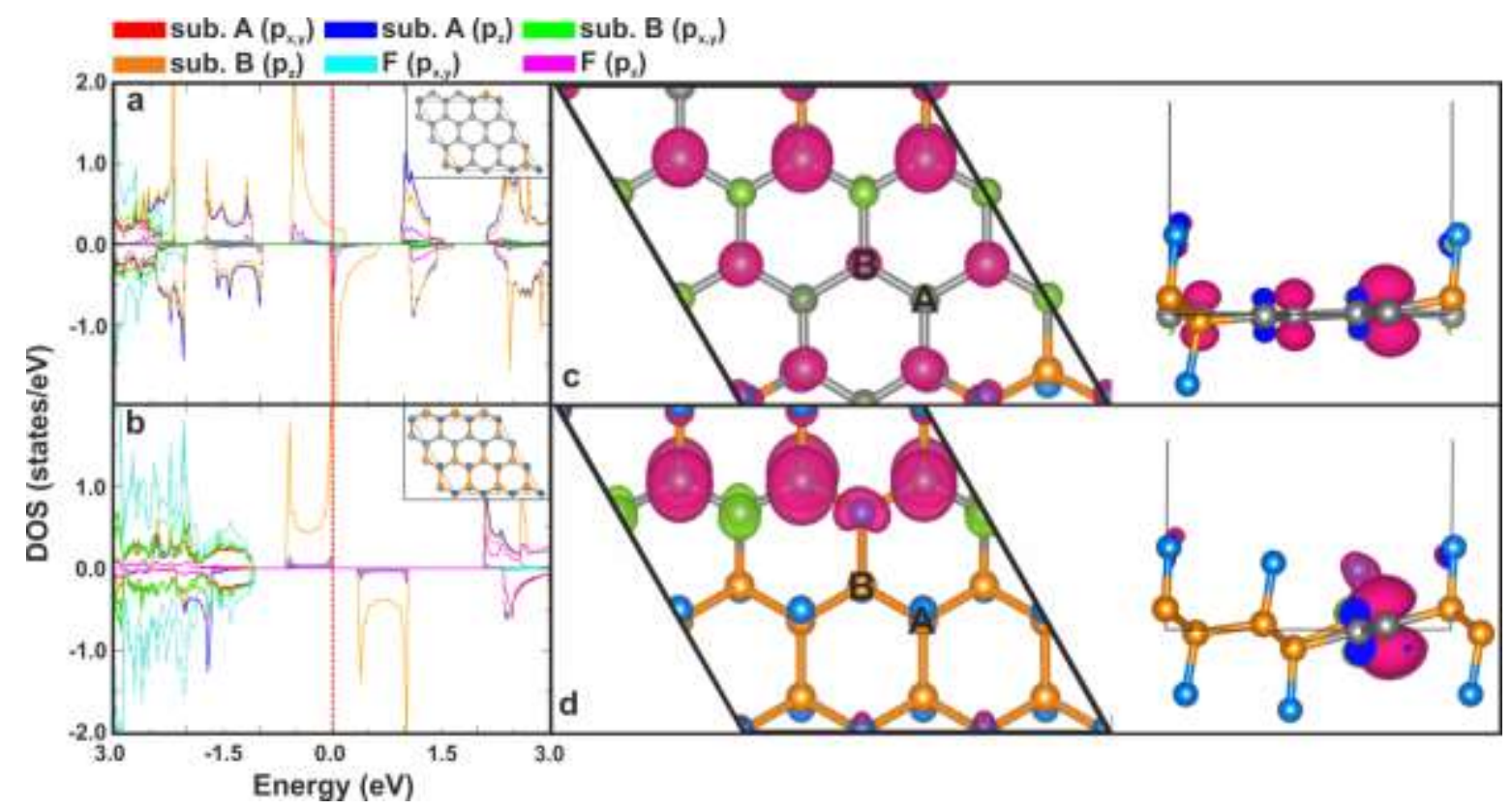

Figure S26. Atoms/orbital resolved density of states of (a) $\mathrm{C}_{18} \mathrm{~F}_{3}$ and (b) $\mathrm{C}_{18} \mathrm{~F}_{13}$. The structures are depicted as insets. Spin density distribution plots of (c) $\mathrm{C}_{18} \mathrm{~F}_{3}$ and (d) $\mathrm{C}_{18} \mathrm{~F}_{13}$. Isovalue \pm 0.005 e $\AA^{-3}$ (positive/negative spin densities are shown in pink/green). The DOS at $E_{F}(\mathrm{a}, \mathrm{b})$ are predominantly composed of $p_{z}$ orbitals of carbon atoms neighboring to fluorine ad-atoms whose $p_{(x, y, z)}$ orbitals also contribute to these states. This allows the magnetic exchange between the F ad-atoms and nearestneighbor substrate $s p^{2} \mathrm{C}$ atoms in analogy with the superexchange interaction as also reviewed by the spin density distributions (c,d). The spin texture extends along the $\pi$-conjugated part of the lattice due to the direct interaction between the carbon atoms carrying antiparallel magnetic moments.

Table S5. Binding energy $E_{\text {bind }}[\mathrm{eV}]$ and magnetic moment $\mu\left[\mu_{B}\right]$ of $\mathrm{C}_{18} \mathrm{~F}_{1}$ calculated using GGA and $\mathrm{GGA}+\mathrm{U}(U=5.00 \mathrm{eV}$ for both $\mathrm{C}$ and $\mathrm{F}$ atoms $)$ calculations with relaxed and fixed magnetic moment. Two $k$-point meshes $5 \times 5 \times 1$ and $15 \times 15 \times 1$ were used.

\begin{tabular}{c|c|c|c|c|}
\hline \multirow{2}{*}{} & \multicolumn{3}{|c|}{ GGA } & \multicolumn{2}{c}{ GGA+U } \\
\cline { 2 - 5 } & Relaxed & Fixed & Relaxed & Fixed \\
\hline \multirow{2}{*}{$E_{\text {bind }}$} & -44.1 & -42.6 & -44.1 & -42.6 \\
\hline$\mu$ & 0.07 & 1.00 & 0.07 & 1.00 \\
\hline \multirow{2}{*}{ Ebind $_{\text {biny }}$} & -44.1 & -42.6 & -44.1 & -42.6 \\
\hline$\mu$ & 0.00 & 1.00 & 0.00 & 1.00 \\
\hline
\end{tabular}




\section{References}

(S1) CCDC (2017). CSD web interface - intuitive, cross-platform, web-based access to CSD data. Cambridge Crystallographic Data Centre, 12 Union Road, Cambridge, UK.

(S2) Zhou, S.; Sherpa, S. D.; Hess, D. W.; Bongiorno, A. Chemical Bonding of Partially Fluorinated Graphene. J. Phys. Chem. C 2014, 118, 26402-26408, DOI:10.1021/jp508965q.

(S3) Kumar, N.; Sharma, J. D.; Ahluwalia, P. K. First-principle Study of Nanostructures of Functionalized Graphene. Pramana 2014, 82, 1103-1117, DOI:10.1007/s12043-014-0758-x. 